\title{
A PROPÓSITO DE LAS ACTITUDES DE LOS JÓVENES MALLORQUINES HACIA EL CASTELLANO Y EL ANDALUZ: DATOS SOBRE LA VALORACIÓN INDIRECTA

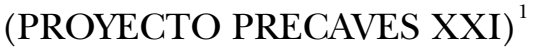

\author{
Beatriz MÉNDEz GuerRero \\ Universidad Autónoma de Madrid (España)
}

\section{RESUMEN}

Las actitudes lingüísticas de los hablantes explican muchas de sus actuaciones lingüísticas y permiten prever hacia dónde se encaminarán las lenguas y sus variedades en los próximos tiempos. Esta investigación, enmarcada en el proyecto PRECAVES XXI, se ha centrado en determinar las actitudes hacia el castellano y andaluz (a través de sus hablantes, su cultura y la región) de 70 jóvenes mallorquines estudiantes de filología. Los principales resultados sugieren que los informantes tienden a jerarquizar la lengua y a relacionar su propia variedad con el modelo idiomático (más prestigioso). También se observa una valoración positiva de las dos variedades, si bien en el caso del castellano casi siempre es mejor y solo observamos puntuaciones más altas en el andaluz en cualidades relacionadas con la solidaridad.

PALABRAS CLAVE: actitudes lingüísticas; variedades cultas; PRECAVES XXI; castellano; andaluz.

\section{ABSTRACT}

The linguistic attitudes of speakers explain many of their linguistic actions and allow us to anticipate the future of languages and their varieties. This research, which forms part of the PRECAVES XXI project, has focused on knowing the attitudes towards Spanish and Andaluz (through its speakers, its culture and its region) of 70 young Majorcan students of philology. The main results suggest that

\footnotetext{
${ }^{1}$ Este trabajo se inscribe en los proyectos de investigación «La población migrante en la Comunidad de Madrid: factores lingüísticos, comunicativos, culturales y sociales del proceso de integración y recursos lingüísticos de intervención» (INMIGRA3-CM) Ref.: H2019/HUM5772, financiado por la Comunidad de Madrid, cofinanciado por el Fondo social Europeo (IP: Florentino Paredes García), y «Estudio de fenómenos de contacto lingüístico en tiempo real y aparente en el castellano de Mallorca» Ref. FFI2017-83899-P (MINECO, AEI/FEDER, UE), financiado por el Ministerio de Ciencia e Innovación (IP: Andrés Enrique Arias).
} 
informants rank the language and associate their own variety with the idiomatic model (which is more prestigious). There is also a positive perception of the two varieties, although in the case of Spanish it is almost always better and we only observe a better assessment of Andaluz in qualities related to solidarity.

KEYWORDS: language attitudes; educated varieties; PRECAVES XXI; Spanish; Andaluz.

Fecha de recepción: $01 / 03 / 2020$

Fecha de aceptación: 08/07/2020

Fecha de la versión definitiva: 18/07/2020

\section{INTRODUCCIÓN}

La vitalidad de las lenguas o las variedades están determinada por las actitudes favorables o desfavorables que se generan hacia ellas (Baker 1992). Estas actitudes, que inciden directamente en el uso, pueden conocerse si se analizan las reacciones de los hablantes y se examinan las cualidades que les asignan (López Morales 2004; Crano y Prislin 2006; Moreno 2012). Al emprender estudios de esta naturaleza, es imprescindible considerar las distintas dimensiones de la actitud. Por una parte, de acuerdo con López Morales (2004), se han de evaluar las percepciones producidas por los pensamientos o creencias de los hablantes hacia las lenguas (dimensión cognitiva); por otra, los sentimientos, estados de ánimo y emociones que les producen (dimensión afectiva); y, en último lugar, las actuaciones, intenciones o conductas que expresan (dimensión conativa).

Muchos de los trabajos presentados hasta la fecha han resaltado el carácter social de las actitudes lingüísticas, lo que las hace estables y generales dentro de una comunidad de hablantes, aunque puedan ir cambiando en algún momento. Asimismo, también han sugerido que estas percepciones son fruto de los estados y procesos cognitivos (siempre subjetivos) de los hablantes, que dan como resultado hipótesis lingüísticas y juicios evaluativos, fundamentados en una reputación adquirida por esa lengua o atribuida por el grupo de hablantes (Preston 1999; Hernández Campoy 2004; Buzón, Gómez y Gómez 2017; Méndez en prensa a y b).

Toda esta información da lugar a posibles predicciones sobre otros comportamientos futuros y permite además conocer el grado de prestigio y solidaridad que asignan los grupos sociales a estas lenguas. Las lenguas más reconocidas o valoradas socialmente tienden a relacionarse, como defienden distintos autores, con un estatus y un prestigio más alto, mientras que las menos valoradas normalmente presentan valores más bajos de prestigio, pero más altos de solidaridad y afiliación dentro de sus comunidades de práctica o de comunidades afines (Henerson, Morris y Fitz-Gibbon 1987; Saville-Troike 2003; Hernández Campoy 2004; Paredes y Cestero 2018). 
Esta investigación se ha servido de los resultados obtenidos por el proyecto PRECAVES XXI en la ciudad de Palma para establecer las actitudes lingüísticas que muestran un grupo de 70 jóvenes filólogos hacia su propia variedad y hacia la variedad andaluza. En concreto, aquí se presentan las valoraciones indirectas hacia las variedades mencionadas, hacia sus hablantes y hacia sus culturas y regiones. La elección del perfil de hablantes (mallorquines jóvenes estudiantes de filología) viene determinada por el hecho de que hasta el momento la mayoría de los estudios de actitudes hacia el castellano y el andaluz se han basado en las percepciones de los hablantes de las zonas «centrales» de la variedad. Este trabajo pretende aportar información de una zona más alejada del habla castellana que pueda compararse con la presentada en otros estudios. Además, que los informantes sean estudiantes de filología posibilita la realización de predicciones sobre el comportamiento de los potenciales futuros transmisores del prestigio lingüístico.

El objetivo fundamental de este trabajo es determinar si el grupo encuestado considera que una de estas variedades es más prestigiosa, si los hablantes de una de estas variedades son mejor valorados (nivel formativo, nivel de ingresos, tipo de trabajo y características individuales) y si la zona y la cultura es mejor o peor considerada. Para obtener estos datos, como se explicará, se ha recurrido a una encuesta de respuesta abierta en algunos momentos y de valoración graduada y escala de diferencial semántico en otros.

\section{LOS ESTUdiOS DE ACTITUDES HACIA EL CASTELLANO Y EL ANDALUZ EN MALlorCa}

Los estudios de actitudes en Mallorca se han centrado hasta el momento en analizar el grado de aceptación del bilingüismo en la zona y en determinar las funciones que han asumido el castellano y el catalán en la comunidad. Actualmente, se considera que la convivencia de las lenguas es buena. En opinión de los hablantes analizados, no existen funciones específicas para cada lengua, puesto que ambas se utilizan en cualquier ámbito. Y, además, la previsión es que la situación se mantenga así y que ninguna lengua se vea reemplazada por la otra. Las escuelas hacen una labor muy importante en este sentido, pues son las encargadas de transmitir que vale la pena aprender las dos lenguas (Pieras-Guasp 2002; Casesnoves y Más 2017).

Existen también, aunque son todavía escasos, algunos estudios centrados en las actitudes que presentan los mallorquines hacia las distintas variedades cultas del español. Estos trabajos han determinado que la variedad castellana se considera más prestigiosa, especialmente la que se habla en 
las grandes ciudades como Madrid. También han permitido establecer una serie de rasgos mejor valorados, muchos de tipo fónico como «es muy clara», «se entiende muy bien» o «es suave» y otros más generales como «cercanía», «familiaridad»o «sencillez». Y, por último, han mostrado resultados más positivos en las valoraciones cognitivas del tipo «el castellano es una variedad clara y urbana» y, en menor medida, en las afectivas como «el castellano es una variedad sencilla, agradable y cercana» (Méndez 2018).

En el caso del andaluz, estos estudios indican que existe un amplio reconocimiento de la variedad por parte de los isleños. Las actitudes que estos muestran son positivas, en especial en los parámetros afectivos (con puntuaciones superiores a las de la variedad castellana) como «sencillez», «cercanía» y «belleza» (y no tanto los cognitivos: «ruralidad», «monotonía», «aspereza», etc.). En relación con la proximidad entre la variedad propia y el andaluz, se concluye que los mallorquines no se sienten próximos o muy identificados con la variedad andaluza (Méndez en prensa a y b). Para encontrar más trabajos relacionados con las actitudes lingüísticas hacia el andaluz, tenemos que recurrir a investigaciones realizadas con hablantes peninsulares. Gallego y Rodríguez (2012) realizaron un estudio a partir de un grupo heterogéneo de castellanos (en total 620 informantes). En él, al igual que en los resultados de los estudios realizados en Mallorca, no se observa un desprestigio de la variedad andaluza. Algo similar se observa también en los trabajos de Cestero y Paredes (2018b) y en el de Yraola (2014). En este último, los informantes madrileños a partir de los que se construyó el estudio indicaron incluso que Andalucía era la región cuyo español más les gustaba (después de la región propia). No obstante, también se menciona que el habla andaluza presenta rasgos que despiertan en los informantes algunas actitudes negativas (como falta de claridad, pérdida de sonidos, etc.). Estas reacciones menos positivas se observan igualmente en otros trabajos con grupos de hablantes castellanos como los de Crespo y Manjón (1996) y Manjón (2000) entre otros.

Así pues, como se ha visto, existen estudios que se han acercado a las actitudes lingüísticas de las variedades castellana y andaluza; sin embargo, nos encontramos con que estos trabajos no responden a otras informaciones necesarias como, por ejemplo, qué opinión les merece a los mallorquines su variedad frente a otras variedades de la misma lengua (como el andaluz) o qué valoraciones realizan hacia los hablantes y hacia la región y la cultura. Este trabajo pretende dar respuesta a alguna de estas cuestiones y presentar los resultados del proyecto PRECAVES XXI en la isla de Mallorca. Las preguntas de investigación se centran en conocer si existe una variedad más prestigiosa para los mallorquines encuestados, si presentan evaluaciones diferentes hacia los hablantes castellanos y andaluces y si consideran mejor una de las culturas o regiones frente a la otra. 


\section{Metodología}

El proyecto PRECAVES XXI tiene como objetivo estudiar las actitudes hacia las variedades cultas del español en distintas zonas hispanohablantes. Para hacerlo, recurre a técnicas directas e indirectas que le ayuden a sortear posibles limitaciones derivadas del uso de solo una de las dos técnicas. De acuerdo con la concepción mentalista se asume que los individuos expresan las actitudes a través de sus reacciones ante estímulos. Por esa razón, se ha expuesto a los sujetos a grabaciones de voces masculinas y femeninas que hacen uso de las distintas variedades cultas del español ${ }^{2}$ para recoger sus reacciones, de carácter evaluativo y discriminatorio, y determinar qué tipo de apreciaciones realizan.

El cuestionario se creó a partir de la técnica de pares falsos o máscaras y la recogida de la muestra se realizó a través de una aplicación informática creada para la ocasión. La prueba consistió en oír dos grabaciones (una de discurso oral y otra de discurso leído) por cada una de las variedades cultas del español y en cumplimentar el cuestionario ${ }^{3}$. La encuesta cuenta con preguntas directas e indirectas, abiertas y cerradas, muchas de ellas a partir de escalas de diferencial semántico, para obtener información sobre percepciones y creencias de los informantes hacia las variedades del español y sobre las actitudes previsibles hacia las mismas (Cestero y Paredes 2018a). El cuestionario está compuesto por 12 preguntas que giran en torno a la valoración directa de la variedad que escuchan, la valoración indirecta de la variedad a través de la persona que habla o lee y la valoración indirecta de la variedad a través de la zona geográfica y la cultura (Cestero y Paredes 2018b).

La evaluación directa de las variedades permite conocer la valoración que hace el hablante sobre la variedad que oye y la proximidad que existe entre esta y la propia. Las preguntas indirectas, por su parte, ofrecen información sobre la variedad a través de sus hablantes, culturas y ciudades o países. De este modo, se puede determinar de qué manera influyen las actitudes hacia la persona que habla en la valoración que se hace de la variedad. Esta parte de la encuesta cuenta, por un lado, con tres preguntas cerradas (de valoración graduada y escala de diferencial semántico), relacionadas con rasgos de la personalidad y la educación de la persona que

\footnotetext{
${ }^{2}$ Centro y norte de España, sur de España, Canarias, México y Centroamérica, Caribe, Andes, Chile y Río de la Plata (Moreno Fernández 2009; Moreno y Otero 2007).

${ }^{3}$ Los encuestados valoraron en total 16 grabaciones, 2 por cada una de las 8 variedades cultas mencionadas en la nota al pie anterior. En este trabajo solo se han tenido en cuenta las 2 grabaciones castellanas (procedentes de hablantes madrileños) y las 2 andaluzas (procedentes de hablantes sevillanos).
} 
habla (grado de inteligencia, simpatía, cercanía, erudición y educación) y con su posible puesto de trabajo, nivel de ingresos y nivel de estudios. Y, por otro lado, otro grupo de preguntas abiertas y de escalas de diferencial semántico, a partir de las cuales se pretende conocer de forma indirecta algunas percepciones acerca del país, la zona o región de la persona que habla y sobre su cultura. Así podemos saber, entre otras cosas, la opinión del informante respecto a la región (retrasada/avanzada, aburrida/ divertida, extraña/familiar, fea/bonita) y la cultura (tradicional/innovadora, pobre/rica, distante/cercana, poco interesante/muy interesante) de esa variedad ${ }^{4}$. En este trabajo, como se ha mencionado ya, nos limitaremos a presentar los resultados del segundo bloque de preguntas de tipo indirecto ${ }^{5}$.

La muestra recogida está compuesta por 70 mallorquines jóvenes estudiantes de filología. Como se aprecia en la Tabla 1, en la página siguiente, disponemos de un porcentaje mayor de mujeres $(84,3 \%)$ que de hombres $(15,7 \%)$, como suele ser habitual en los estudios de filología, todos ellos con edades comprendidas entre los 18-20 años (52,9\%) y entre 20-30 años $(47,1 \%)$. La mayor parte de los informantes no cuenta con formación dialectal $(72,8 \%)$, pero muchos han tenido contacto tanto con personas de la variedad castellana $(64,3 \%)$ como de la variedad andaluza $(75,7 \%)^{6} \mathrm{y}$, además, también han tenido contacto frecuente con otras regiones peninsulares en las que se hace uso de dichas variedades $(68,6 \%)$. Respecto a la lengua materna de los encuestados, predominan los castellanohablantes $(67,1 \%)$ frente a los catalanohablantes $(28,6 \%)$ o a los que manejan ambas lenguas por igual $(4,3 \%)$.

Las variables independientes del estudio son la variedad (castellanaandaluza), el sexo (hombre-mujer), el colectivo (con conocimientos dialectales-sin conocimientos dialectales), la voz evaluada (masculina-femenina), la lengua materna (castellano-catalán), el discurso (oral-escrito), el contacto con hablantes de la variedad de otros lugares (con contacto-sin contacto) y el contacto con otras ciudades en las que se utilice la variedad (contacto frecuente-poco/nulo contacto).

${ }^{4}$ La elección de preguntas cerradas y de diferencial semántico en algunos momentos de la encuesta viene determinada por las ventajas que este tipo de preguntas presenta a la hora de codificar, comparar y tratar estadísticamente los datos y por la uniformidad que proporciona a las respuestas. También evita la obtención de respuestas vagas o imprecisas.

${ }^{5}$ Los resultados de la valoración directa pueden consultarse en Méndez (en prensa a).

${ }^{6}$ Cuando los informantes indican que conocen a hablantes de esa variedad se refieren, en el caso del castellano, principalmente a madrileños u otros hablantes del centro-norte peninsular y, en el caso del andaluz, a cualquier hablante que provenga de la comunidad autónoma andaluza. 
TABLA 1. Muestra

\begin{tabular}{|c|c|c|c|}
\hline \multirow{2}{*}{ Sexo } & Hombres & 11 & $15,7 \%$ \\
\hline & Mujeres & 59 & $84,3 \%$ \\
\hline \multirow{2}{*}{ Edad } & Menores de 20 años & 37 & $52,9 \%$ \\
\hline & 20 años o más & 33 & $47,1 \%$ \\
\hline Profesión & Estudiantes & 70 & $100 \%$ \\
\hline Lugar de origen & España (Palma de Mallorca) & 70 & $100 \%$ \\
\hline \multirow{2}{*}{ Colectivo } & Estudiantes sin formación dialectal & 51 & $72,8 \%$ \\
\hline & Estudiantes con formación dialectal & 19 & $27,2 \%$ \\
\hline \multirow{3}{*}{ Lengua materna } & Castellano & 47 & $67,1 \%$ \\
\hline & Catalán & 20 & $28,6 \%$ \\
\hline & Ambas* & 3 & $4,3 \%$ \\
\hline \multirow{2}{*}{$\begin{array}{l}\text { Contacto } \\
\text { con la variedad }\end{array}$} & Sí & $45 / 53^{7}$ & $64,3 \% / 75,7 \%$ \\
\hline & No & $25 / 17$ & $35,7 \% / 24,3 \%$ \\
\hline \multirow{2}{*}{$\begin{array}{l}\text { Contacto } \\
\text { con la región }\end{array}$} & Contacto frecuente & 48 & $68,6 \%$ \\
\hline & Escaso/nulo contacto & 22 & $31,4 \%$ \\
\hline \multicolumn{2}{|l|}{ TOTAL } & 70 & $100 \%$ \\
\hline
\end{tabular}

* Este grupo no será tenido en cuenta en la investigación por no ser apenas representativo en la muestra.

\section{ACTITUDES DE LOS MALLORQUINES HACIA LAS VARIEDADES CASTELLANA}

$$
\text { Y ANDALUZA }
$$

Presentamos a continuación los resultados de las 3 preguntas de investigación que hemos planteado al principio del trabajo: ¿existe una variedad más prestigiosa?, ¿qué valoraciones reciben las voces castellanas y andaluzas? y ¿qué valoraciones reciben la región y la cultura?

\subsection{Prestigio de las variedades castellana y andaluza}

Para determinar si los 70 informantes del estudio percibían alguna variedad como mejor o más prestigiosa, se les planteó la siguiente pregunta de respuesta abierta: ¿en qué región o zona se habla mejor el español? ${ }^{8}$

${ }^{7}$ El primer dato hace referencia a la variedad castellana y el segundo a la andaluza.

8 También se les pidió que identificaran la variedad de las voces que escuchaban. En el caso del castellano la identificación de la variedad fue total y en el del andaluz rozó el $85 \%$ (Méndez en prensa a). 
TABLA 2. Zonas más prestigiosas

\begin{tabular}{ccc}
\cline { 2 - 3 } & \multicolumn{2}{c}{ Prestigio Variedad } \\
\cline { 2 - 3 } Castellana & Frecuencia & Porcentaje \\
\hline Castilla & $\mathbf{3 4}$ & $\mathbf{4 8 , 6}$ \\
\hline Centro/Norte & 5 & 11,4 \\
\hline Noreste & 5 & 7,2 \\
\hline Madrid & 1 & 1,4 \\
\hline Valladolid & 10 & 14,4 \\
\hline Toledo & 3 & 4,3 \\
\hline Salamanca & 3 & 4,3 \\
\hline Barcelona & 2 & 2,8 \\
\hline Castellón & 1 & 1,4 \\
\hline España & 1 & 1,4 \\
\hline Otros & $\mathbf{6}$ & $\mathbf{8 , 7}$ \\
\hline Monolingües & 1 & $\mathbf{2 , 8}$ \\
\hline Educación & 1 & 1,4 \\
\hline Todas igual & $\mathbf{2 4}$ & 1,4 \\
\hline No responde & $\mathbf{4}$ & $\mathbf{3 4 , 3}$ \\
\hline TOTAL & $\mathbf{7 0}$ & $\mathbf{5 , 6}$ \\
\hline
\end{tabular}

Los resultados indican que un $60,1 \%$ de los encuestados cree que existe alguna variedad mejor frente a un $34,3 \%$ que piensa que todas las variedades son igual de prestigiosas y un $5,6 \%$ que no contesta. Dentro de la consideración de variedad más prestigiosa, tiene más peso la creencia de que el castellano es el mejor español $(48,6 \%)$. Las regiones, zonas o ciudades mejor valoradas son Madrid (14,4\%), Castilla (11,4\%), el centro/norte peninsular $(7,2 \%)$, Valladolid $(4,3 \%)$, Toledo $(4,3 \%)$, Salamanca $(2,8 \%)$, el noreste peninsular $(1,4 \%)$, Barcelona $(1,4 \%)$ y Castellón $(1,4 \%)$. Como puede apreciarse, en ningún caso se menciona el territorio propio como zona más prestigiosa de español. Probablemente, ello se deba a la percepción que tienen los hablantes de encontrarse en una zona periférica de habla castellana, alejada de las grandes ciudades o grandes núcleos urbanos con los que relacionan estos informantes el habla más prestigiosa. El hecho, además, de que la variedad se encuentre en contacto con otra lengua puede influir también en la consideración de que no debe verse como el modelo idiomático. 
TABLA 3. Jerarquía/no jerarquía a partir de las variables independientes

\begin{tabular}{l|cc|cc}
\cline { 2 - 5 } \multicolumn{1}{c}{ Sexo } & \multicolumn{2}{c|}{ Mejor Variedad } & \multicolumn{2}{c}{ No Mejor Variedad } \\
& Hombres & Mujeres & Hombres & Mujeres \\
\multirow{2}{*}{ Discurso } & $6(54,5 \%)$ & $36(61 \%)$ & $5(45,6 \%)$ & $14(23,7 \%)$ \\
\hline \multirow{2}{*}{ Voz evaluada } & Oral & Escrito & Oral & Escrito \\
& $30(42,9 \%)$ & $21(30 \%)$ & $12(17,1 \%)$ & $12(17,1 \%)$ \\
\hline \multirow{2}{*}{ Colectivo } & Masculina & Femenina & Masculina & Femenina \\
& $17(51,5 \%)$ & $25(67,6 \%)$ & $14(42,4 \%)$ & $10(27 \%)$ \\
\hline \multirow{2}{*}{ Lengua materna } & Con formación & Sin formación & Con formación & Sin formación \\
& $9(47,4 \%)$ & $33(64,7 \%)$ & $10(52,6 \%)$ & $14(27,4 \%)$ \\
\hline \multirow{2}{*}{ Contacto } & Castellano & Catalán & Castellano & Catalán \\
con la variedad & $27(57,4 \%)$ & $12(60 \%)$ & $16(34 \%)$ & $7(35 \%)$ \\
& Contacto & Sin contacto & Contacto & Sin contacto \\
& $25(55,5 \%) /$ & $17(68 \%) /$ & $16(35,5 \%) /$ & $7(28 \%) /$ \\
& $31(58,5 \%)$ & $12(70,6 \%)$ & $19(35,8 \%)$ & $5(29,4 \%)$ \\
\hline \multirow{2}{*}{ Contacto } & Contacto & Escaso/nulo & Contacto & Escaso/nulo \\
con la región & frecuente & contacto & frecuente & contacto \\
& $24(50 \%)$ & $12(54,5 \%)$ & $16(33,3 \%)$ & $8(36,4 \%)$ \\
\hline
\end{tabular}

Si tenemos en cuenta las distintas variables que manejamos en el estudio en relación con el hecho de si existe o no una mejor variedad, observamos que, aunque con poca diferencia, son las mujeres las que piensan mayormente que existe una variedad más prestigiosa (61\% frente al $54,5 \%$ de los hombres $)^{9}$. Es en el discurso oral donde se tiende a pensar más que existe una mejor variedad (42,9\% frente al $30 \%$ del discurso escrito) y en la evaluación de las voces femeninas $(67,6 \%$ frente al $51,5 \%$ de las voces masculinas). El colectivo sin formación dialectal también considera con más frecuencia que hay una mejor variedad $(64,7 \%$ frente al $47,4 \%$ con formación dialectal) y también lo creen así, pero con una diferencia mínima, los informantes que tienen el catalán como lengua materna ( $60 \%$ frente al $57,4 \%)$. Son, asimismo, las personas sin contacto con hablantes castellanos y andaluces de otras comunidades autónomas los que perciben la existencia

9 Este dato coincide con el obtenido en trabajos pertenecientes a otras ciudades que siguen esta misma metodología, donde se observa la misma tendencia por parte de las mujeres a valorar mejor la pauta de pronunciación que suelen considerar modelo idiomático normativo (la variedad castellana). Para más información, consúltese Hernández y Samper (2018), Méndez (2018) y Paredes y Cestero (2018). 
de variedades más prestigiosas: $68 \%$ (hablantes castellanos de otras zonas) y 70,6\% (hablantes andaluces) frente al 55,5\% (hablantes castellanos de otras zonas) y $58,5 \%$ (hablantes andaluces de otras zonas). De igual modo, son los informantes que no han viajado a otras regiones en las que se utilizan estas variedades (54,5\% frente al $50 \%$ de los que sí han viajado) los que perciben una variedad (el castellano) como más prestigiosa o un modelo idiomático de referencia.

Los datos mostrados en este apartado permiten concluir que casi 2 tercios de los encuestados perciben que existe un español mejor que coincide con su propia variedad frente a un tercio que opina que no debe verse una jerarquía entre las distintas variedades. Los análisis estadísticos realizados con SPSS v.25 indican que la voz evaluada $\left(\chi^{2}=9,711 ; p\right.$-value $\left.=0,046\right)$, el colectivo con/sin formación dialectal $\left(\chi^{2}=14,436\right.$; $p$-value $\left.=0,006\right)$ y la lengua materna $\left(\chi^{2}=170,702 ; p\right.$-value $\left.=0,000\right)$ influyen significativamente en las actitudes presentadas.

\subsection{Valoración de las variedades castellana y andaluza a través de sus hablantes}

La valoración indirecta de las variedades castellana y andaluza se centró en preguntas relacionadas con las actitudes hacia los hablantes de estas variedades. En este sentido, se les solicitó que valoraran, por una parte, el puesto de trabajo, el nivel de ingresos y el nivel de estudios de las voces que escuchaban; y, por otra parte, las cualidades que le asignan a la persona (inteligente-poco inteligente, simpática-antipática, cercana-distante, cultainculta, educada-maleducada) ${ }^{10}$.

Los resultados sugieren que la variedad castellana recibe mejores puntuaciones en todos los campos. En el caso del puesto de trabajo, la media de la variedad castellana es de 2,26 en una escala del 1 (poco cualificado) al 3 (altamente cualificado), mientras que la de la variedad andaluza es de $1,71^{11}$. Concretamente, en solo 8 casos se percibió la persona que hablaba castellano como "poco cualificada», en 85 casos como «bien cualificada», en 45 casos como «altamente cualificada» y en 2 casos no se respondió a la pregunta. Y en el caso de la variedad andaluza se consideró «poco cualificada» en 46 ocasiones, «bien cualificado» en 87 ocasiones, «altamente cualificado» en 6 ocasiones y en 1 no se contestó.

${ }^{10}$ Aquí contamos con 140 respuestas por cada variedad, pues son 2 grabaciones las que cada informante escucha de cada variedad (una del discurso oral y otra del leído) como se ha indicado ya.

${ }^{11}$ El punto de inflexión sería 2, por tanto, las puntuaciones de los andaluces deben verse como negativas. 
Figura 1. Valoración/Prestigio de sus hablantes

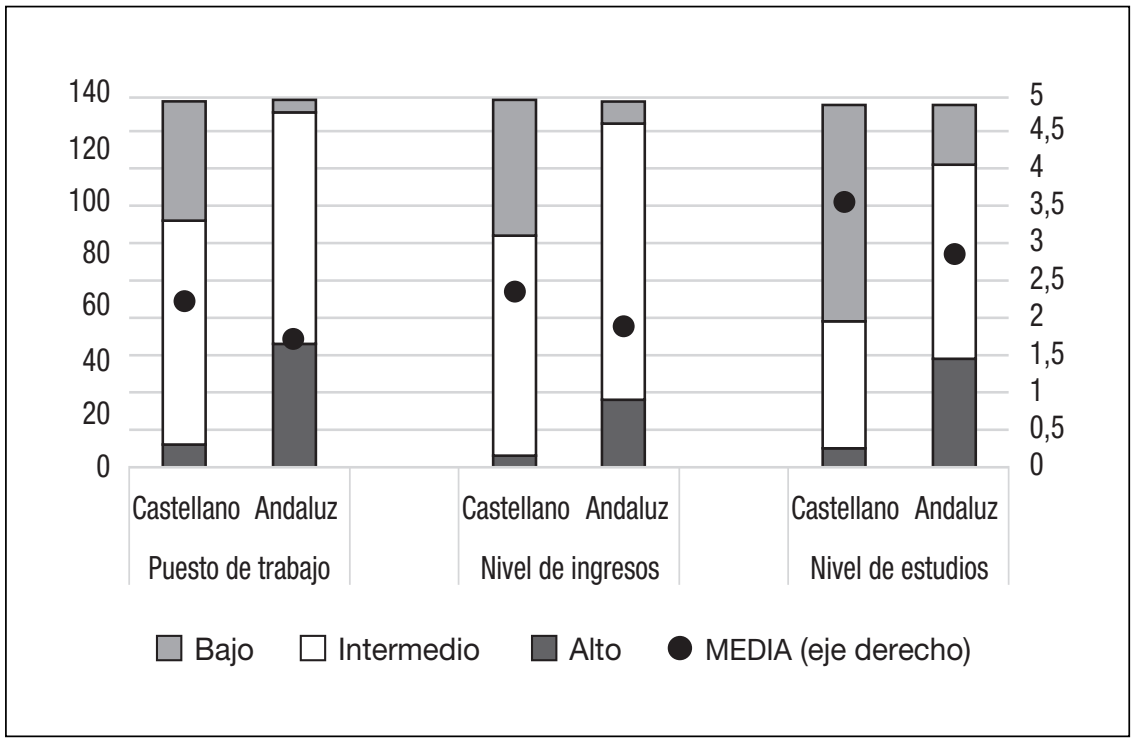

En cuanto a los ingresos, las medias indican igualmente una mejor valoración de la variedad castellana 2,34 frente a la andaluza 1,86 ${ }^{12}$ en una escala del 1 (bajo) al 3 (alto). En particular, son tan solo 4 los casos en los que se percibe que los ingresos de la persona castellana que habla son bajos, en 83 casos se piensa que los ingresos son medios, en 52 casos que son altos y en 1 caso no se contesta. Por su parte, en la variedad andaluza los casos en los que se perciben ingresos bajos para la persona andaluza que habla aumentan a 26, en 104 ocasiones se creen que los ingresos son medios, en tan solo 8 casos se cree que los ingresos de la persona son altos y en 2 casos no hay respuesta.

Los resultados relativos al nivel de estudios no son muy diferentes a los datos expresados previamente. Las medias establecidas del 1 (sin estudios) al 4 (estudios universitarios) son de nuevo más altas para las voces castellanas $(3,54)$ que para las andaluzas $(2,84)$, siendo 2,5 el punto de inflexión. En el caso de la persona castellana que habla, se considera que todos tienen formación académica: en 7 casos estudios primarios, en 48 casos estudios secundarios, en 82 estudios universitarios y en 3 casos no contestan. Mientras que en el caso de las voces andaluzas hay 2 casos en los que se considera que la persona que habla no tiene ningún tipo de formación, en 41 casos

${ }^{12}$ Este dato también es negativo al estar por debajo de 2. 
tienen estudios primarios, en 73 casos tienen estudios secundarios, en 23 tienen estudios universitarios y en 1 caso no responden.

Desde un punto de vista estadístico, la variedad demuestra ser significativa en todos los casos: trabajo $\left(\chi^{2}=56,585 ; p\right.$-value $\left.=0,000\right)$, ingresos $\left(\chi^{2}=50,755 ; p\right.$-value $\left.=0,000\right)$ y estudios $\left(\chi^{2}=64,390 ; p\right.$-value $\left.=0,000\right)$.

TABLA 4. Valoración de los hablantes castellanos a partir de las variables independientes

\begin{tabular}{l|cc|cc|cc}
\hline CASTELLANA & \multicolumn{2}{|c|}{ Trabajo } & \multicolumn{2}{c|}{ Ingresos } & \multicolumn{2}{c}{ Estudios } \\
\hline \multirow{2}{*}{ Sexo } & Hombres & Mujeres & Hombres & Mujeres & Hombres & Mujeres \\
& 2,38 & 2,25 & 2,52 & 2,31 & 3,61 & 3,53 \\
\hline \multirow{2}{*}{ Discurso } & Oral & Escrito & Oral & Escrito & Oral & Escrito \\
& 2,27 & 2,26 & 2,32 &, 36 & 3,60 & 3,48 \\
\hline Voz & Masculina & Femenina & Masculina & Femenina & Masculina & Femenina \\
evaluada & 2,53 & 2,02 & 2,59 & 2,12 & 3,80 & 3,31 \\
\hline \multirow{4}{*}{ Colectivo } & Con & Sin & Con & Sin & Con & Sin \\
& 2,57 & 2,15 & 2,63 & 2,23 & 3,78 & 3,45 \\
\hline Lengua & Castellano & Catalán & Castellano & Catalán & Castellano & Catalán \\
materna & 2,21 & 2,33 & 2,33 & 2,37 & 3,51 & 3,61 \\
\hline Contacto & Contacto & Sin contacto & Contacto & Sin contacto & Contacto & Sin contacto \\
con la & personas & personas & personas & personas & personas & personas \\
variedad & 2,19 & 2,40 & 2,31 & 2,40 & 3,55 & 3,53 \\
\hline Contacto & Contacto & Escaso/nulo & Contacto & Escaso/nulo & Contacto & Escaso/nulo \\
con la & frecuente & contacto & frecuente & contacto & frecuente & contacto \\
región & 2,33 & 2,11 & 2,38 & 2,25 & 3,60 & 3,43 \\
\hline
\end{tabular}

Si tenemos en cuenta las distintas variables independientes en relación con la valoración de la persona que habla, observamos que en el caso del castellano son los hombres los que hacen una mejor valoración media del puesto de trabajo, del nivel de ingresos y del nivel de estudios. Las diferencias son más pequeñas en el caso del tipo de discurso, donde la puntuación media es ligeramente más alta en el discurso oral en relación con el puesto de trabajo y en el nivel de estudios, pero no así en el nivel de ingresos, donde la puntuación media más alta es para el discurso escrito. El colectivo con formación dialectal es quien asigna mejores puntuaciones medias en las tres categorías. En la lengua materna también se observan diferencias, son los informantes con el catalán como lengua materna los que mejores puntuaciones otorgan en el trabajo, los ingresos y en el nivel académico. 
Las valoraciones indirectas en relación con el contacto de los informantes con personas de esa variedad no aportan resultados relevantes en el caso del castellano y además no muestran una tendencia clara: por una parte, los informantes sin contacto con otras personas castellanohablantes de otras ciudades presentan valoraciones más altas en las categorías puesto de trabajo y en nivel de ingresos, pero no en nivel de estudios donde son los encuestados que tienen contacto con castellanohablantes de otras regiones los que mejor puntuación asignan, aunque con una diferencia mínima. Ya, por último, las puntuaciones medias más altas en relación con la variable contacto con la región son las producidas por los informantes que han viajado con frecuencia a otras ciudades castellanohablantes. Esos datos se aprecian tanto en el nivel de estudios como en el de ingresos y estudios.

Se observa significatividad entre las actitudes hacia el trabajo, los ingresos y la formación y la variable voz evaluada: trabajo $\left(\chi^{2}=29,071 ; p\right.$-value $=$ $0,000)$, ingresos $\left(\chi^{2}=28,918 ; p\right.$-value $\left.=0,000\right)$, estudios $\left(\chi^{2}=24,385 ; p\right.$-value $=$ $0,000)$; y colectivo con/sin formación dialectal: trabajo $\left(\chi^{2}=18,656\right.$; $p$-value $=0,000)$, ingresos $\left(\chi^{2}=18,202 ;\right.$-value $\left.=0,000\right)$, estudios $\left(\chi^{2}=8,825\right.$; p-value $=0,012)$.

TABLA 5. Valoración de los hablantes andaluces a partir de las variables independientes

\begin{tabular}{l|cc|cc|cc}
\hline ANDALUZA & \multicolumn{2}{|c|}{ Trabajo } & \multicolumn{2}{c|}{ Ingresos } & \multicolumn{2}{c}{ Estudios } \\
\hline Sexo & Hombres & Mujeres & Hombres & Mujeres & Hombres & Mujeres \\
& 1,81 & 1,61 & 1,81 & 1,87 & 2,77 & 2,85 \\
\hline \multirow{2}{*}{ Discurso } & Oral & Escrito & Oral & Escrito & Oral & Escrito \\
& 1,64 & 1,78 & 1,76 & 1,97 & 2,67 & 3,01 \\
\hline Voz & Masculina & Femenina & Masculina & Femenina & Masculina & Femenina \\
evaluada & 1,55 & 1,85 & 1,81 & 1,91 & 2,65 & 3,01 \\
\hline & Con & Sin & Con & Sin & Con & Sin \\
Colectivo & formación & formación & formación & formación & formación & formación \\
& 1,54 & 1,77 & 1,84 & 1,88 & 2,63 & 2,92 \\
\hline Lengua & Castellano & Catalán & Castellano & Catalán & Castellano & Catalán \\
materna & 1,68 & 1,76 & 1,83 & 1,92 & 2,78 & 3,00 \\
\hline Contacto & Contacto & Sin contacto & Contacto & Sin contacto & Contacto & Sin contacto \\
con la & personas & personas & personas & personas & personas & personas \\
variedad & 1,71 & 1,61 & 1,88 & 1,84 & 2,86 & 2,80 \\
\hline Contacto & Contacto & Escaso/nulo & Contacto & Escaso/nulo & Contacto & Escaso/nulo \\
con la & frecuente & contacto & frecuente & contacto & frecuente & contacto \\
región & 1,66 & 1,81 & 1,84 & 1,92 & 2,84 & 2,83 \\
\hline
\end{tabular}


En el caso de la variedad andaluza, los datos son algo diferentes y las puntuaciones medias son siempre más bajas. Aquí son las mujeres, salvo en el puesto de trabajo, las que mejores valoraciones hacen hacia los hablantes de esta variedad. En relación con el tipo de discurso, las mejores valoraciones se obtienen siempre en el discurso leído. Nuevamente, estos datos contrastan con los presentados sobre los hablantes castellanos, en los que en dos de las tres categorías las mejores puntuaciones las obtenía el discurso oral. Este dato resulta especialmente interesante ya que la variedad propia siempre es mejor valorada a través del discurso oral y, en cambio, aquí se observa que en la variedad ajena (la andaluza) se valora mejor el discurso leído ${ }^{13}$. Habrá que determinar en futuros trabajos si esta tendencia a valorar mejor el discurso escrito en las variedades ajenas se observa en otras ciudades. En el caso de la voz evaluada, se aprecia cómo reciben mejores valoraciones las voces femeninas. Una vez más llaman la atención las diferencias en las valoraciones de los hablantes andaluces y castellanos. Como se recordará, en el caso de la variedad castellana recibían puntuaciones mucho más altas las voces masculinas que las femeninas. Respecto al colectivo, una vez más vuelven a verse diferencias respecto a la variedad castellana, pues se observa que las mejores valoraciones las realiza el colectivo sin formación dialectal. Los catalanohablantes son en este caso, al igual que ocurría con la variedad castellana, los que mejores valoraciones presentan en las tres categorías. Son asimismo los informantes que tienen contacto con andaluces los que mejor calificación les otorgan. Este dato tampoco coincide con la valoración de las voces que hablan en el caso de la variedad castellana. Por último, en relación con las valoraciones atendiendo la variable contacto con la región, son los informantes que apenas han viajado a ciudades andaluzas, salvo en el nivel de estudios aunque con una diferencia mínima, los que valoran más positivamente a los andaluces. Puede apreciarse que en estas valoraciones indirectas existe una tendencia por parte de los informantes mallorquines a relacionar ciertos rasgos como mejores hacia su variedad (por ejemplo, que las voces masculinas son más capaces o están mejor formadas y posicionadas laboralmente). Y, frente a ello, en la variedad andaluza, que es vista como menos prestigiosa y con valoraciones no tan positivas hacia sus hablantes, se valoran mejor otros rasgos (por ejemplo, las voces femeninas). Lo mismo ocurre con el perfil de informantes que valora mejor cada variedad, en el caso del castellano, los hombres con formación dialectal sin contacto habitual con otros hablantes de la varie-

${ }^{13}$ En trabajos similares realizados en otras ciudades también se observa esta tendencia a una mejor valoración de la variedad propia a través del discurso oral. Para más información, véanse los trabajos de Paredes y Cestero (2018) en la zona centro-norte peninsular, Manjón (2018) en la ciudad de Granada y Santana (2018a) en Sevilla. 
dad; y, en el caso del andaluz, las mujeres sin formación dialectal que tienen contacto frecuente con hablantes andaluces. Por ende, en la mayoría de los casos, los informantes no solo otorgan valoraciones de distinta magnitud a las variantes, sino que incluso invierten el orden de valoración en las dos variedades ${ }^{14}$.

Vuelven a presentarse en el andaluz, a nivel estadístico, algunas relaciones significativas. Estas son muy claras en el tipo de discurso: trabajo $\left(\chi^{2}=6,444\right.$; $p$-value $=0,040)$, ingresos $\left(\chi^{2}=7,000 ; p\right.$-value $\left.=0,030\right)$ y estudios $\left(\chi^{2}=10,879\right.$; $p$-value $=0,012)$. Y también en voz evaluada: trabajo $\left(\chi^{2}=11,779 ; p\right.$-value $=$ $0,003)$, estudios $\left(\chi^{2}=11,448 ; p\right.$-value $\left.=0,010\right)$; y en colectivo con $/$ sin formación dialectal: trabajo $\left(\chi^{2}=8,233 ; p\right.$-value $\left.=0,016\right)$, estudios $\left(\chi^{2}=8,925\right.$; p-value $=0,030)$.

FigURA 2. Valoración de los hablantes a partir de sus cualidades personales

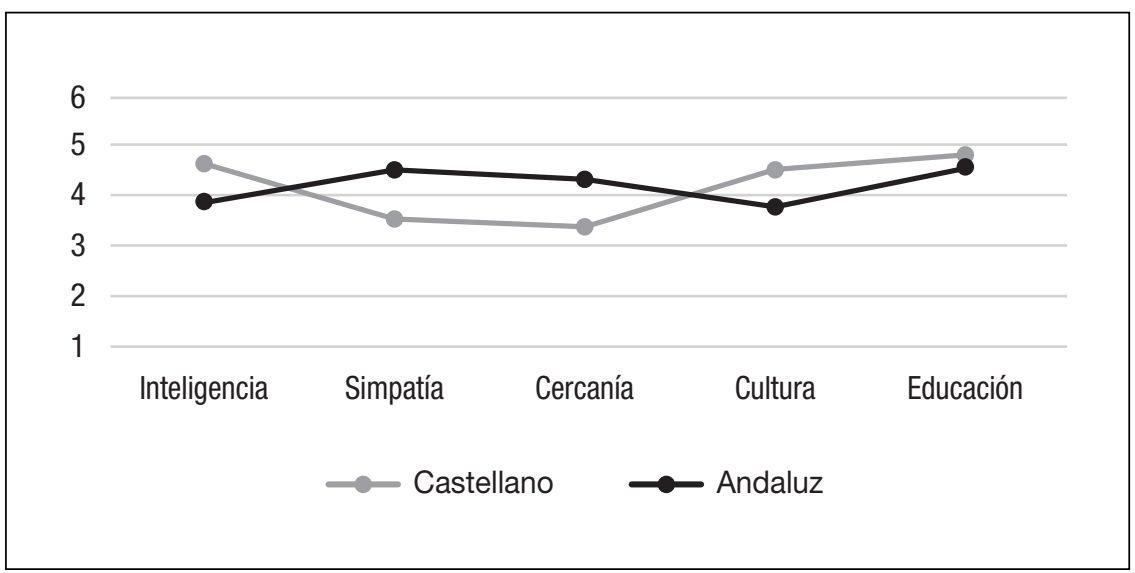

En cuanto a las características personales que asignan los informantes mallorquines a las voces castellanas y andaluzas también observamos diferencias. En una escala del 1 (extremadamente poco) al 6 (extremadamente alto $)^{15}$, las medias más altas en las cualidades de inteligente $(4,63$ frente a

${ }^{14}$ Es importante recordar también que, como se ha indicado en el apartado 1 de este trabajo, en un estudio previo centrado en las valoraciones directas se observó que la variedad andaluza recibía mejores valoraciones que la castellana a nivel afectivo y la castellana era mejor valorada a nivel cognitivo; y que, dependiendo de la variedad, al igual que ocurre aquí, se veían ciertos rasgos como más positivos y eran perfiles diferentes de hablantes los que las asignaban (Méndez en prensa a).

15 Punto de inflexión: 3,5. 
$3,85)$, educado $(4,84$ frente a 4,55$)$ y culto $(4,55$ frente a 3,72$)$ se las otorgan a los hablantes castellanos. Y las calificaciones más elevadas otorgadas a la variedad andaluza corresponden a las cualidades simpático (4,52 frente a 3,50$)$ y cercano $(4,32$ frente a 3,36$)$, todas ellas cualidades más cercanas a un sentimiento de solidaridad. Adicionalmente, a partir de las respuestas abiertas de los encuestados, se ha podido determinar que se asignan a las personas castellanas cualidades como: educadas, claras, precisas, profesionales, cultas, formadas, serias, amables, distantes, agradables, cosmopolitas, ocupadas, inteligentes, afables, calmadas, serenas, cercanas, secas, alegres, pesimistas, independientes, familiares, aburridas, pedantes, frías e intolerantes. A las personas andaluzas, por su parte, las consideran: espontáneas, abiertas, simpáticas, graciosas, educadas, cercanas, inteligentes, con carácter, sencillas, buena gente, trabajadoras, hospitalarias, escandalosas, lentas, familiares, confiables, dicharacheras, de habla rápida, dinámicas, eficientes, geniales, cotillas, bruscas, sociables, alegres, risueñas, generosas, respetables, variadas, extrovertidas, vagas, comunicativas, habladoras, agresivas, amigables y expresivas. Estas diferencias resultan estadísticamente significativas en todos los casos, salvo en la cualidad educada-maleducada ${ }^{16}$ : inteligente-poco inteligente $\left(\chi^{2}=45,585 ; p\right.$-value $\left.=0,000\right)$, simpática-antipática $\left(\chi^{2}=53,732 ; p\right.$-value $\left.=0,000\right)$, cercana-distante $\left(\chi^{2}=37,934 ; p\right.$-value $\left.=0,000\right)$, culta-inculta $\left(\chi^{2}=42,465 ; p\right.$-value $\left.=0,000\right)$.

$\mathrm{Si}$ atendemos las variables independientes, observamos que en el caso de la variedad castellana la cualidad de inteligente es principalmente asignada por los hombres, al discurso escrito, a voces masculinas, por el colectivo con conocimientos dialectales, por los catalanohablantes, por los informantes que tienen contacto con otros hablantes peninsulares de la variedad y por los encuestados que viajan habitualmente a otras ciudades castellanas. En el caso de las cualidades de simpática y culta, ocurre lo mismo (salvo en la variable «contacto con la variedad»). La cualidad de cercana solo varía de las anteriores en que son las mujeres las que proporcionan mejores puntuaciones. Por último, la cualidad de educada vuelve a ser mejor valorada por las mujeres, como en el caso anterior, y además es la ocasión en que el discurso oral recibe una puntuación más alta y las personas que no viajan con frecuencia a otras ciudades castellanas proporcionan una mayor valoración.

Algunos de los resultados anteriores muestran una relación estadística significativa. Este es el caso de inteligente-voz evaluada $\left(\chi^{2}=30,611 ; p\right.$-value $=$ $0,000)$, inteligente-colectivo con/sin formación dialectal $\left(\chi^{2}=12,970\right.$; $p$-value $=0,011)$, cercana-voz evaluada $\left(\chi^{2}=11,278\right.$; $p$-value $\left.=0,046\right)$, cercanasexo del informante $\left(\chi^{2}=11,185 ; p\right.$-value $\left.=0,048\right)$, culta-voz evaluada

${ }^{16}\left(\chi^{2}=8,771 ; p\right.$-value $\left.=0,067\right)$. 


\begin{tabular}{|c|c|c|c|c|c|c|c|c|c|c|c|c|c|}
\hline 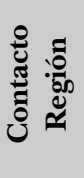 & $\stackrel{0}{\mathbf{z}}$ & & 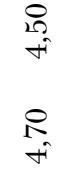 & $\begin{array}{l}\hat{N} \\
\text { on } \\
0 \\
0 \\
\infty\end{array}$ & $\begin{array}{c}20 \\
2 \\
01 \\
0 \\
20 \\
00 \\
00\end{array}$ & 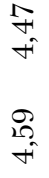 & $\begin{array}{l}\infty \\
\infty \\
+ \\
\vec{\infty} \\
+\end{array}$ & & $\begin{array}{l}\frac{\pi}{0} \\
+ \\
0 \\
0 \\
\infty\end{array}$ & $\begin{array}{l}\stackrel{f}{f} \\
f \\
6 \\
\stackrel{8}{f}\end{array}$ & $\left|\begin{array}{c}0 \\
\infty \\
f \\
\infty \\
\infty \\
f\end{array}\right|$ & $\begin{array}{c}\infty \\
\infty \\
\infty \\
\approx \\
0 \\
\infty\end{array}$ & 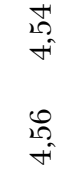 \\
\hline 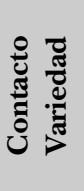 & $\ddot{z}$ & & $\begin{array}{l}10 \\
10 \\
+1 \\
\infty \\
0 \\
0 \\
8\end{array}$ & $\begin{array}{l}\vec{b} \\
\infty \\
\infty \\
\infty \\
\infty\end{array}$ & $\begin{array}{l}\infty \\
\infty \\
\infty \\
\infty \\
\infty \\
\infty \\
\infty\end{array}$ & 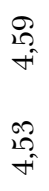 & $\begin{array}{l}\hat{N} \\
+ \\
N \\
\infty \\
+\end{array}$ & & $\begin{array}{l}8 \\
0 \\
\text { की } \\
\text { की } \\
\text { की }\end{array}$ & $\begin{array}{l}\text { की } \\
\text { fo } \\
\text { fi } \\
\text { fi }\end{array}$ & 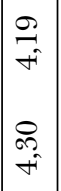 & $\begin{array}{l}\infty \\
\infty \\
\infty \\
\infty \\
\infty \\
\infty \\
\infty\end{array}$ & $\begin{array}{l}\infty \\
\infty \\
+i \\
10 \\
0 \\
+i\end{array}$ \\
\hline$\Xi$ & త్ & & 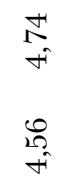 & $\begin{array}{l}0 \\
\infty \\
\infty \\
F \\
\Rightarrow\end{array}$ & $\begin{array}{l}\vec{b} \\
00 \\
\vec{v} \\
\vec{v} \\
\infty\end{array}$ & $\begin{array}{l}\mathscr{b} \\
\stackrel{+}{+} \\
\infty \\
\stackrel{+}{+}\end{array}$ & 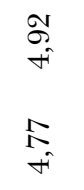 & & $\begin{array}{l}\text { Or } \\
\stackrel{+}{7} \\
0 \\
0 \\
\text { on }\end{array}$ & 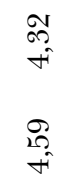 & 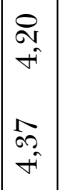 & $\begin{array}{l}8 \\
\infty \\
\sigma \\
\infty \\
\infty\end{array}$ & 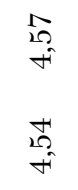 \\
\hline ن⿺辶ِ & $\frac{\sqrt{1}}{\sqrt{2}}$ & & 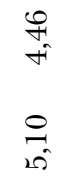 & $\begin{array}{l}\infty \\
\infty \\
\infty \\
\infty \\
\infty \\
\infty\end{array}$ & $\begin{array}{l}2 \\
\tilde{N} \\
\infty \\
\infty \\
\infty \\
0 \\
\infty \\
\infty\end{array}$ & $\begin{array}{l}\not{F} \\
\vec{\sigma} \\
\stackrel{\leftrightarrow}{+}\end{array}$ & $\begin{array}{l}\stackrel{9}{R} \\
f \\
\hat{\sigma} \\
\hat{\sigma}\end{array}$ & & $\begin{array}{l}8 \\
\text { of } \\
\frac{1}{1} \\
\text { का }\end{array}$ & 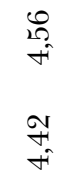 & $\begin{array}{l}F \\
\underset{f}{f} \\
0 \\
\underset{f}{-}\end{array}$ & $\begin{array}{l}\infty \\
\infty \\
\infty \\
\infty \\
\infty \\
\infty \\
\infty\end{array}$ & 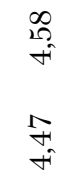 \\
\hline$\nu^{N}$ & 工 & & 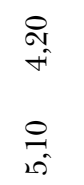 & $\begin{array}{l}\text { N } \\
\text { on } \\
\infty \\
\infty \\
\text { of }\end{array}$ & $\begin{array}{l}0 \\
0 \\
0 \\
\delta \\
0 \\
0 \\
\infty\end{array}$ & $\begin{array}{l}0 \\
\stackrel{+}{+} \\
\infty \\
\stackrel{+}{+}\end{array}$ & $\begin{array}{l}88 \\
\stackrel{8}{+1} \\
0 \\
0\end{array}$ & & $\begin{array}{l}8 \\
f \\
\infty \\
0 \\
0\end{array}$ & 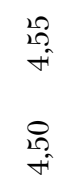 & 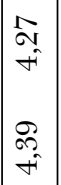 & $\begin{array}{l}\overrightarrow{0} \\
\dot{f} \\
0 \\
\infty \\
\text { की }\end{array}$ & 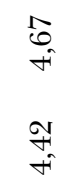 \\
\hline 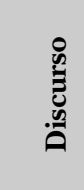 & 0 & & $\begin{array}{l}\mathscr{8} \\
\stackrel{+}{+} \\
\stackrel{8}{8} \\
+\end{array}$ & 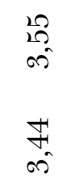 & $\begin{array}{l}\frac{1}{4} \\
\infty \\
0 \\
\sim \\
\infty \\
\infty\end{array}$ & 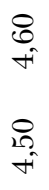 & $\begin{array}{l}\stackrel{20}{f} \\
f \\
\text { O } \\
+\end{array}$ & & $\begin{array}{l}8 \\
\text { of } \\
\infty \\
\infty \\
\text { of }\end{array}$ & 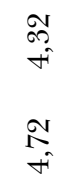 & $\begin{array}{c}\infty \\
\infty \\
\infty \\
\sim \\
0 \\
f \\
f\end{array}$ & $\begin{array}{l}\frac{1}{1} \\
\infty \\
\infty \\
0 \\
\infty\end{array}$ & $\begin{array}{l}10 \\
10 \\
7 \\
10 \\
10 \\
7\end{array}$ \\
\hline 离 & $\Sigma$ & & 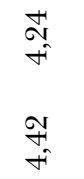 & $\begin{array}{l}\vec{a} \\
\text { v } \\
\sigma \\
\overrightarrow{0}\end{array}$ & $\begin{array}{l}\infty \\
i \infty \\
\infty \\
\infty \\
\infty \\
N \\
\infty\end{array}$ & 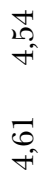 & 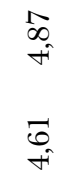 & & $\begin{array}{l}\infty \\
\infty \\
\text { on } \\
8 \\
\text { की } \\
\text { की }\end{array}$ & 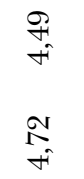 & 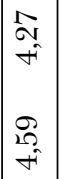 & $\begin{array}{l}0 \\
\infty \\
\infty \\
0 \\
\infty \\
\infty\end{array}$ & 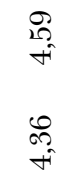 \\
\hline & & 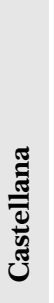 & 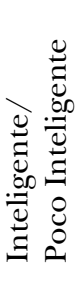 & 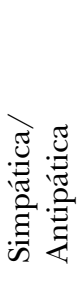 & 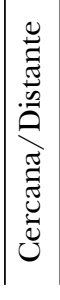 & 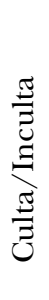 & 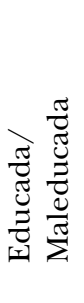 & 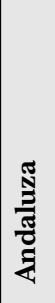 & 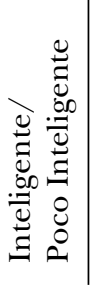 & 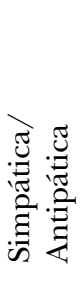 & 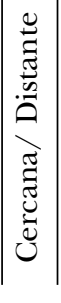 & 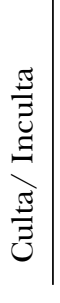 & 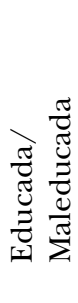 \\
\hline
\end{tabular}


$\left(\chi^{2}=27,109 ; p\right.$-value $\left.=0,000\right)$, culta-colectivo con $/ \sin$ formación dialectal $\left(\chi^{2}=10,917 ; p\right.$-value $\left.=0,028\right)$, culta-lengua materna $\left(\chi^{2}=79,124 ;\right.$-value $=$ $0,050)$, educada-voz evaluada $\left(\chi^{2}=14,017 ; p\right.$-value $\left.=0,003\right)$ y educada-lengua materna $\left(\chi^{2}=61,738 ; p\right.$-value $\left.=0,049\right)$.

Las valoraciones de las voces andaluzas presentan diferencias, como ya se apuntaba anteriormente. La cualidad de inteligente es mejor valorada por las mujeres, a diferencia de lo que ocurría con las voces castellanas. Son el discurso escrito y las voces femeninas los que presentan valoraciones más altas, este último dato también contrasta con los anteriores donde siempre se valoraba más positivamente a las voces masculinas. Es el colectivo sin formación dialectal (como ya ocurría en el caso de la valoración del puesto de trabajo, los ingresos y los estudios) el que propone puntuaciones más altas, una vez más esta información contrasta con la obtenida sobre las voces castellanas. Además, son los catalanohablantes y los informantes con contacto con andaluces los que mejor puntúan. Y, a diferencia de las voces castellanas, los que no tienen contacto con la región son los que más alto puntúan. En la cualidad de simpatía, son los hombres los que más alto puntúan y es el discurso oral el mejor valorado, este último dato contrasta con el obtenido para las voces castellanas donde el discurso escrito se valoraba mejor en esta categoría. Se repite el dato de las voces femeninas con mejor puntuación, este dato contrasta también con los observados en la variedad castellana, donde en ningún caso se valoró mejor la voz femenina. Son el colectivo sin formación dialectal y los castellanohablantes los que presentan mejores valoraciones (otra vez en contraposición a los datos sobre las voces castellanas) y los que no tienen contacto con andaluces, pero sí han viajado con frecuencia a Andalucía lo que más les asignan esta cualidad. Respecto a la cercanía, vuelven a ser los hombres y el discurso oral los mejor valorados, datos que contrastan con las voces castellanas donde eran las mujeres y el discurso escrito los que mejor valoración recibían. Por primera vez en el caso de las voces andaluzas, se observa que las mejores valoraciones son para las voces masculinas. Son el colectivo sin formación dialectal y los castellanohablantes los que mejores puntuaciones asignan en esta categoría (otra vez observamos diferencias respecto a las voces castellanas aquí). Y los que tienen contacto con andaluces, pero no viajan con frecuencia los que más alto puntúan (este último dato también supone un contraste respecto a los hablantes castellanos). La cualidad culta presenta algunas diferencias respecto a la anterior, pues son las mujeres las que mejor valoran (al contrario también que en las voces castellanas). El discurso escrito y las voces femeninas asimismo reciben mejor puntuación, este último dato también opuesto al de los hablantes castellanos. El colectivo sin formación dialectal, los catalanohablantes y los informantes que tienen contacto con andaluces, pero no viajan con frecuencia a Andalucía también otorgan 
puntuaciones más altas aquí. En el caso de las voces castellanas, como se recordará, eran el colectivo con formación dialectal, los hablantes sin contacto con castellanos peninsulares y los que viajaban con frecuencia a otras ciudades castellanas los que mejor valoraban las voces. Por último, la cualidad de educada presenta puntuaciones más elevadas en las variables mujer, voz femenina, colectivo sin formación dialectal, catalanohablantes, contacto con andaluces y contacto frecuente con la región. En este caso, no hay diferencia en la valoración que se hace del tipo de discurso. Las diferencias que se observan respecto a la valoración de las voces castellanas están en las variables discurso (se valora mejor el oral), voz evaluada, colectivo con/sin formación dialectal y contacto con la región ${ }^{17}$. En este caso las relaciones estadísticamente significativas son inferiores: cercana-tipo de discurso $\left(\chi^{2}=\right.$ $18,473 ; p$-value $=0,002)$, culta-voz evaluada $\left(\chi^{2}=15,433 ; p\right.$-value $\left.=0,009\right)$ y culta-colectivo con/sin formación dialectal $\left(\chi^{2}=13,158 ; p\right.$-value $\left.=0,022\right)$.

\subsection{Valoración de las variedades castellana y andaluza a través de la región y la cultura}

El estudio de la valoración indirecta de las variedades castellana y andaluza se completa con el análisis de las respuestas acerca de la opinión que les merece la región y la cultura de las voces (castellanas y andaluzas) que escuchan. Por una parte, se les solicitó a los informantes que valoraran la zona de la que creían que era la persona que hablaba (avanzada-retrasada, divertida-aburrida, familiar-extraña, bonita-fea); y, por otra, que mostraran su opinión sobre la cultura de esa zona (innovadora-tradicional, rica-pobre, cercana-distante, interesante-poco interesante).

Los resultados obtenidos ponen de manifiesto una serie de diferencias en las valoraciones de los hablantes hacia las dos variedades analizadas. En primer lugar, en relación con la zona o región, se observan mejores puntuaciones medias en una escala de 1 (extremadamente retrasado/aburrido/ extraño/feo) a 6 (extremadamente avanzado/divertido/familiar/bonito) ${ }^{18}$ para el castellano en la categoría avanzada (4,48 frente a 3,87 del andaluz) y mejores puntuaciones para el andaluz en el resto de categorías: divertida (4,63 frente a 4,23 del castellano), familiar (4,68 frente a 4,36 del castellano) y bonita (4,92 frente a 4,83 del castellano). Por su parte, en las

${ }^{17}$ El hecho de que sea el mismo perfil de hablantes (castellanohablantes, con formación dialectal y con contacto con la región) los que otorgan mejores puntuaciones a la variedad castellana y peores a la variedad andaluza refuerza la idea que se presentaba en el apartado 3.1 según la cual los informantes perciben ciertas variedades como más prestigiosas que otras.

${ }^{18}$ El punto de inflexión se encuentra en el 3,5. 
FIGURA 3. Valoración de los hablantes a partir de la región y la cultura

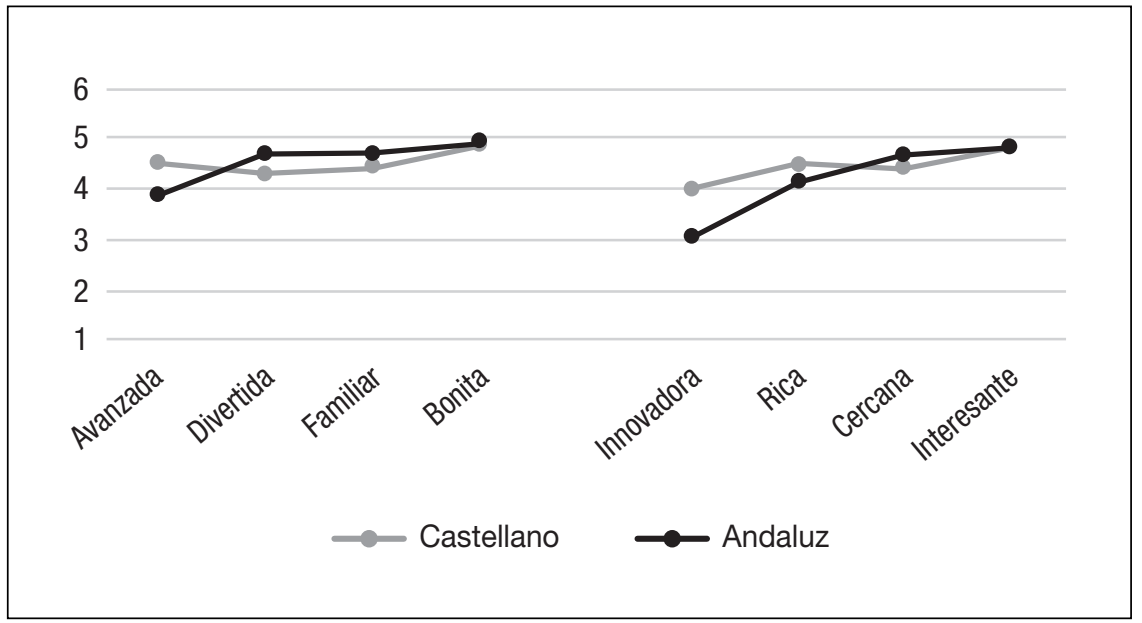

valoraciones indirectas hacia la cultura, las mejores puntuaciones para el castellano se obtienen en las categorías innovadora (3,93 frente a 3,07 del andaluz), rica (4,49 frente a 4,05 del andaluz) e interesante $(4,78$ frente a 4,77 del andaluz), esta última sin apenas diferencia. Y el andaluz es mejor valorado en cercanía (4,64 frente a 4,37 del castellano). Desde un punto de visto estadístico, la distinta variedad se considera una variable significativa en relación con cuatro categorías, dos relativas a la región: avanzadaretrasada $\left(\chi^{2}=24,854 ; p\right.$-value $\left.=0,000\right)$ y divertida-aburrida $\left(\chi^{2}=16,055\right.$; $p$-value $=0,007) ;$ y dos vinculadas a la cultura: innovadora-tradicional $\left(\chi^{2}=\right.$ $38,112 ; p$-value $=0,000)$ y rica-pobre $\left(\chi^{2}=14,673 ; p\right.$-value $\left.=0,012\right)$. Estos datos coinciden nuevamente con los observados en otros estudios de actitudes hacia el castellano y en el andaluz, donde la variedad andaluza siempre es vista como más divertida, familiar, bonita y cercana, incluso por los propios informantes andaluces (Santana 2018b).

Si tenemos en cuenta las variables independientes en relación con la variedad castellana, observamos que son las mujeres y los castellanohablantes los que presentan mejores valoraciones en las 4 categorías vinculadas a la región. En cuanto al discurso se valora mejor el oral en la categoría avanzado y el escrito en el resto. La voz evaluada masculina recibe mejor valoración en todos los casos menos en familiar y el colectivo con formación dialectal otorga puntuaciones más altas, al igual que el caso anterior, menos en la categoría familiar. Respecto al contacto con personas castellanas de otras ciudades, en todos los casos (salvo en avanzada) es el grupo que sí tiene contacto el que mejores valoraciones realiza. Por último, solo en el 


\begin{tabular}{|c|c|c|c|c|c|c|c|c|c|c|c|c|c|c|c|c|c|c|}
\hline 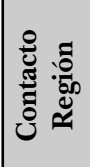 & $\dot{z}$ & 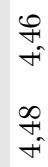 & 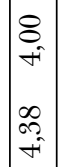 & 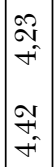 & $\begin{array}{l}\infty \\
\infty \\
+ \\
\alpha \\
\infty \\
\infty \\
+\end{array}$ & $\mid \begin{array}{c}0 \\
R \\
\infty \\
8 \\
8 \\
\dot{f}\end{array}$ & 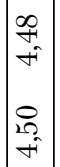 & 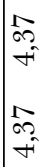 & $\begin{array}{l}0 \\
i \\
i \\
i \\
i\end{array}$ & & $\begin{array}{ll}\infty & 0 \\
2 & 0 \\
\infty & \\
+1 & \\
\infty & 1 \\
\infty & 1\end{array}$ & 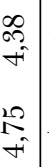 & 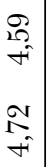 & $\begin{array}{c}5 \\
0 \\
20^{\circ}\end{array}$ & $\begin{array}{l}8 \\
\infty \\
\infty \\
8 \\
\infty\end{array}$ & $\begin{array}{l}8 \\
\text { of } \\
= \\
F\end{array}$ & 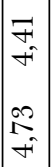 & $\begin{array}{l}\infty \\
\stackrel{\infty}{+} \\
\infty \\
\infty \\
+\end{array}$ \\
\hline 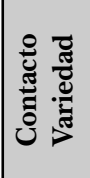 & $\dot{z}$ & 贲 & 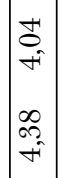 & 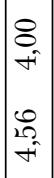 & 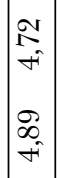 & $\begin{array}{c}\mid \\
\mathscr{8} \\
f \\
0 \\
\infty \\
\infty \\
\infty\end{array}$ & 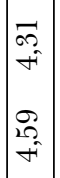 & 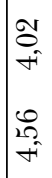 & $\begin{array}{l}\stackrel{10}{1} \\
+ \\
8 \\
+ \\
+\end{array}$ & & \begin{tabular}{l|l}
$\sigma$ & 0 \\
$\infty$ & \\
$\infty$ & \\
$\infty$ & \\
$\infty$ & \\
$\infty$ &
\end{tabular} & 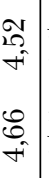 & 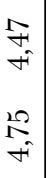 & $\begin{array}{l}20 \\
\sigma \\
+\end{array}$ & $\begin{array}{l}\infty \\
0 \\
\infty \\
5 \\
0 \\
\infty\end{array}$ & 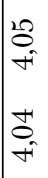 & $\begin{array}{l}\sqrt{2} \\
+ \\
\hat{6} \\
+ \\
+\end{array}$ & $\begin{array}{l}\hat{0} \\
+ \\
\infty \\
\infty \\
+\end{array}$ \\
\hline$\Xi$ & \begin{tabular}{|l|}
$\tilde{J}$ \\
$\tilde{J}$ \\
$\tilde{J}$
\end{tabular} & 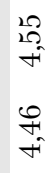 & 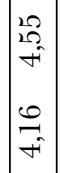 & 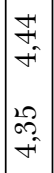 & $\begin{array}{c}20 \\
0 \\
20 \\
0 \\
0 \\
7 \\
7\end{array}$ & $\begin{array}{l}\vec{\infty} \\
\infty \\
\infty \\
\infty \\
\infty \\
\infty\end{array}$ & $\mid \begin{array}{c}\infty \\
1 \\
+ \\
20 \\
20 \\
+ \\
+\infty\end{array}$ & 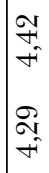 & $\begin{array}{l}\circ \\
20 \\
8 \\
8 \\
+1\end{array}$ & & 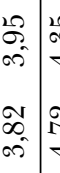 & 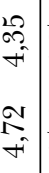 & 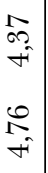 & $\begin{array}{l}10 \\
\infty \\
+ \\
+4\end{array}$ & $\begin{array}{l}20 \\
a \\
0 \\
0 \\
\hat{\sigma} \\
\hat{v}\end{array}$ & $\begin{array}{l}20 \\
7 \\
20 \\
\infty \\
\infty\end{array}$ & 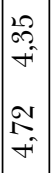 & \begin{tabular}{l}
$\hat{N}$ \\
\multirow{+}{*}{} \\
$\stackrel{9}{*}$ \\
$\stackrel{9}{*}$
\end{tabular} \\
\hline نُ & $\begin{array}{l}\frac{1}{\infty} \\
\frac{1}{0} \\
0\end{array}$ & 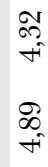 & 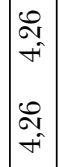 & $\begin{array}{l}F \\
F \\
20 \\
F \\
F\end{array}$ & $\begin{array}{l}\infty \\
\infty \\
+ \\
+ \\
0 \\
\infty \\
+ \\
+\end{array}$ & $\begin{array}{l}\infty \\
i \\
\infty \\
z \\
z \\
f \\
f\end{array}$ & $\begin{array}{l}20 \\
02 \\
7 \\
0 \\
0 \\
0 \\
+\end{array}$ & 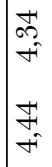 & $\begin{array}{l}R \\
i \\
i \\
i \\
F\end{array}$ & & $\begin{array}{l}8 \\
\infty \\
\infty \\
\infty \\
\infty \\
\infty \\
\infty\end{array}$ & 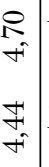 & 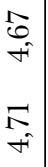 & \begin{tabular}{l}
$\mathscr{f}$ \\
\multirow{+}{*}{}
\end{tabular} & $\begin{array}{l}\infty \\
0 \\
\infty \\
20 \\
\infty \\
\infty\end{array}$ & 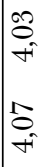 & $\mid \begin{array}{l}20 \\
12 \\
+ \\
6 \\
\infty \\
+ \\
+1\end{array}$ & $\begin{array}{l}\infty \\
+ \\
10 \\
\stackrel{10}{+}\end{array}$ \\
\hline$\stackrel{N}{0}^{2}$ & $\Sigma$ & $\begin{array}{l}\exists \\
F \\
\infty \\
\infty \\
\dot{f}\end{array}$ & 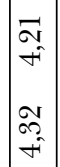 & $\begin{array}{l}F \\
F \\
\approx \\
\approx \\
\dot{f}\end{array}$ & 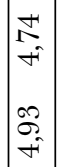 & 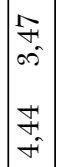 & 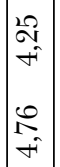 & $\begin{array}{l}\hat{N} \\
\hat{y} \\
\hat{f} \\
\hat{f} \\
\dot{f}\end{array}$ & \begin{tabular}{l}
$\infty$ \\
$\stackrel{\infty}{f}$ \\
$\infty$ \\
$\infty$ \\
\multirow{r}{*}{}
\end{tabular} & & \begin{tabular}{l|l}
$\infty$ & \\
$\infty$ & \\
$\infty$ & \\
$\infty$ & \\
$\delta_{1}$ & \\
$\infty$ &
\end{tabular} & 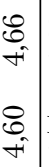 & 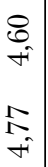 & $\begin{array}{l}\vec{\sigma} \\
\dot{+}\end{array}$ & $\begin{array}{l}0 \\
\cdots \\
\infty \\
\infty \\
o \\
o v\end{array}$ & $\begin{array}{l}\exists \\
F \\
\infty \\
\infty \\
\infty\end{array}$ & 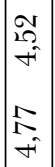 & $\begin{array}{l}\mathscr{\infty} \\
\stackrel{+}{+} \\
0 \\
\stackrel{f}{+}\end{array}$ \\
\hline 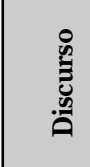 & 0 & 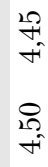 & 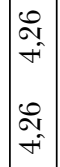 & 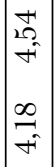 & $\begin{array}{l}\hat{S} \\
\sigma \\
F \\
\tilde{f} \\
f\end{array}$ & $\begin{array}{c}8 \\
\dot{f} \\
8 \\
\infty \\
\infty \\
\infty\end{array}$ & $\begin{array}{l}8 \\
8 \\
f \\
8 \\
\infty \\
+\end{array}$ & $\begin{array}{l}20 \\
20 \\
7 \\
\infty \\
-5 \\
7\end{array}$ & 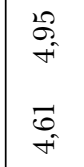 & & $\begin{array}{c}\infty \\
\infty \\
\infty \\
\infty \\
8 \\
\sigma^{\prime} \\
\infty\end{array}$ & 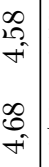 & 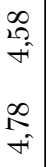 & $\begin{array}{l}10 \\
\infty \\
\sigma^{-1}\end{array}$ & $\begin{array}{l}\infty \\
\infty \\
o i \\
\hat{v} \\
\hat{N} \\
\infty \\
\infty\end{array}$ & $\begin{array}{l}8 \\
\stackrel{f}{0} \\
\infty \\
\underset{f}{+}\end{array}$ & $\begin{array}{l}\overrightarrow{1} \\
F \\
0 \\
20 \\
F\end{array}$ & $\begin{array}{l}\stackrel{R}{+} \\
\stackrel{+}{+} \\
\stackrel{+}{+}\end{array}$ \\
\hline 离 & $\Sigma$ & 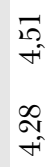 & 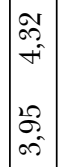 & 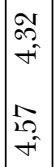 & $\begin{array}{l}20 \\
\infty \\
f \\
0 \\
1 \\
f\end{array}$ & $\begin{array}{l}\hat{\sigma} \\
\infty \\
\sigma^{\prime} \\
\vec{N} \\
\infty\end{array}$ & $\begin{array}{l}\overrightarrow{20} \\
f \\
\infty \\
\infty \\
-2 \\
f\end{array}$ & 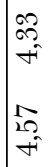 & $\begin{array}{l}\infty \\
\infty \\
+ \\
+ \\
\infty \\
\stackrel{+}{+}\end{array}$ & & 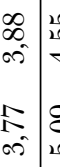 & $\begin{array}{l}20 \\
10 \\
+ \\
8 \\
8 \\
20\end{array}$ & $\begin{array}{l}\mathscr{B} \\
+ \\
\infty \\
\stackrel{f}{+} \\
\dot{f}\end{array}$ & $\begin{array}{l}\mathscr{\delta} \\
+\end{array}$ & $\begin{array}{l}\vec{b} \\
\infty \\
\infty \\
\hat{n} \\
\infty \\
\infty\end{array}$ & 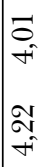 & $\begin{array}{l}8 \\
\dot{f} \\
-\infty \\
\infty \\
+\end{array}$ & $\begin{array}{l}\mathbb{N} \\
+ \\
8 \\
8 \\
10\end{array}$ \\
\hline & & 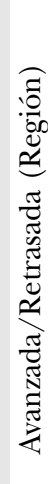 & 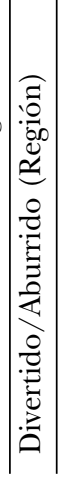 & 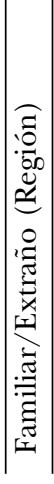 & 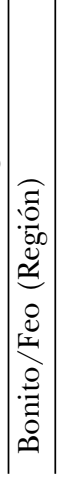 & 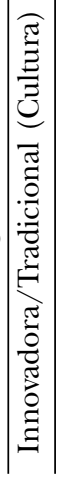 & 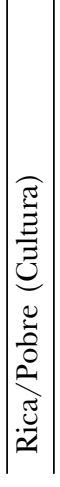 & 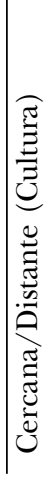 & 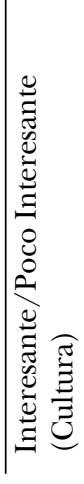 & & 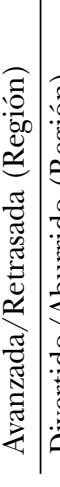 & 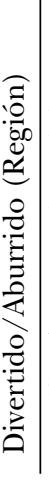 & 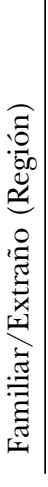 & 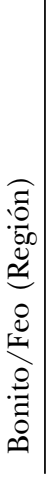 & 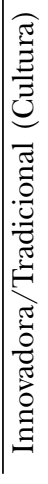 & 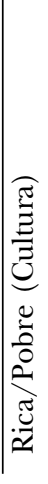 & 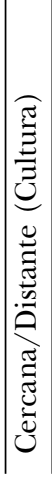 & 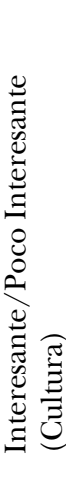 \\
\hline
\end{tabular}


caso de bonito, observamos que son las personas que no viajan con frecuencia a otras ciudades castellanas peninsulares las que mejor puntuación asignan. La cultura, por su parte, es mejor puntuada por las mujeres menos en la categoría cercana. También son mejor valorados el discurso escrito y la voz masculina. Es el colectivo con formación dialectal, exceptuando en la categoría interesante, quien mejor puntúa la cultura castellana y son los catalanohablantes (menos en innovadora) los que mejor la valoran. Respecto a las variables contacto con otras personas de la variedad y contacto con la región, tan solo en el caso de la categoría innovadora (contacto con la variedad) fue mejor la valoración de las personas sin contacto frecuente.

Estadísticamente, resultan significativas las siguientes relaciones: avanzada-voz evaluada $\left(\chi^{2}=21,678 ; p\right.$-value $\left.=0,001\right)$, avanzada-lengua materna $\left(\chi^{2}=31,222 ; p\right.$-value $\left.=0,008\right)$, divertida-contacto región $\left(\chi^{2}=29,467 ; p\right.$-value $=$ $0,014)$, divertida-lengua materna $\left(\chi^{2}=25,928\right.$; $p$-value $\left.=0,039\right)$, innovadoravoz evaluada $\left(\chi^{2}=21,970 ; p\right.$-value $\left.=0,001\right)$ y rica-voz evaluada $\left(\chi^{2}=10,356\right.$; p-value $=0,035)$.

En relación con la evaluación de la variedad andaluza a partir de su región, las mujeres valoran mejor las categorías avanzada y familiar y los hombres divertida y bonita. Las mejores puntuaciones se las lleva de forma unánime el discurso oral y, en la mayoría de las ocasiones, son las personas sin formación dialectal (salvo en familiar) los que mejor la valoran. En el caso de las voces evaluadas, encontramos dos ítems en los que son mejor valoradas las femeninas (divertida y bonita) y dos las masculinas (avanzada y familiar). Salvo en la categoría avanzada son los catalanohablantes, las personas que tienen contacto con hablantes castellanos de otras ciudades y los que viajan con frecuencia los que mejor valoran la cultura castellana. Respecto a la valoración de la cultura andaluza, son los hombres y las personas que viajan frecuentemente a Andalucía los que mejores puntuaciones presentan. El discurso oral y las voces femeninas reciben mejores valoraciones, salvo en la categoría cercana. Esto mismo ocurre con los catalanohablantes. El colectivo con formación dialectal valora mejor los ítems innovadora e interesante y los informantes que tienen contacto con andaluces valoran mejor la cercanía y lo interesante de la cultura.

Los datos sobre las percepciones andaluzas que se acaban de presentar contrastan parcialmente con los del castellano. Las principales diferencias se observan en la mayor predominancia de las mujeres, los castellanohablantes y los informantes con formación dialectal como los que mejores puntuaciones asignan al castellano y el discurso escrito y las voces masculinas como las mejor valoradas en castellano. A nivel estadístico, observamos muy poca significatividad. Aparece solo en un caso relacionado con la región (bonitocontacto con la región: $\chi^{2}=32,584 ; p$-value $\left.=0,001\right)$ y en otro asociado a la cultura (interesante-contacto con la región: $\chi^{2}=27,831 ; p$-value $=0,006$ ). 


\section{Conclusiones}

En este trabajo se han estudiado las actitudes lingüísticas indirectas de un grupo de jóvenes filólogos mallorquines hacia las variedades castellana y andaluza. El objetivo era determinar si sus valoraciones son positivas hacia las dos variedades y si existen diferencias notables entre ambas. De igual modo, se ha querido determinar si este grupo considera que existe una variedad del español mejor que otra y, de ser así, con qué variedad o variedades se asociaría este ideal.

En relación con esta última cuestión, se ha comprobado que 2 tercios de los encuestados consideran que existe una variedad mejor entre las 8 variedades cultas sobre las que se les preguntó: esa variedad corresponde con la propia, el castellano. En este sentido, se ha determinado además que estas evaluaciones resultan significativas estadísticamente si se vinculan a las variables voz evaluada (masculina/femenina), colectivo (con/sin formación dialectal) y lengua materna (castellano/catalán).

En cuanto a las actitudes indirectas hacia las variedades castellana y andaluza, en general se puede decir que son buenas, aunque en prácticamente todos los casos se observa que son entre medio punto y un punto superiores en la variedad castellana. Estas diferencias, además, según el análisis estadístico, son significativas. La valoración indirecta de las variedades a partir de las personas que hablan permite concluir que el puesto de trabajo, el nivel de ingresos y el nivel de estudios muestran relaciones estadísticamente significativas junto a las variables voz evaluada y colectivo con/sin formación dialectal en el caso del castellano; y además lo es también, junto a las anteriores, el tipo de discurso (oral o escrito) en el caso del andaluz. En cuanto a las características personales asignadas a las voces, se observan a su vez diferencias que, en casi todos los casos, son significativas dependiendo de la variedad que se esté evaluando en ese momento. Adicionalmente, en las voces castellanas encontramos otras relaciones estadísticas, la mayoría asociadas a la voz evaluada, al colectivo con/sin formación dialectal y a la lengua materna y, en una ocasión, el sexo del hablante. Por su parte, en las voces andaluzas, las relaciones entre variables estadísticamente significativas son algo menores, pero se mantienen en aquellas variables que han resultado significativas anteriormente: voz evaluada, tipo de discurso y colectivo con/sin formación dialectal. Respecto a la valoración indirecta de las variedades a través de la región y la cultura, se observa algo interesante, por primera vez es la variedad andaluza la que obtiene mejores valoraciones en algunas de las cualidades: divertida, familiar y bonita (región) y cercana (cultura). Por su parte, la variedad castellana presenta puntuaciones superiores en la categoría avanzada (región) y en innovadora, rica e interesante (cultura). Algunas de estas relaciones resultan 
estadísticamente significativas. Una vez más tanto en el caso del castellano son las variables voz evaluada y lengua materna las más influyentes y aquí se une también la variable contacto con la región tanto en el castellano como en el andaluz.

De todo lo anterior se deduce que los hablantes del estudio, en su mayoría, tienen una visión jerárquica de la variación lingüística y asignan a su variedad, a través de sus hablantes, de la región y de la cultura, una serie de rasgos que consideran prestigiosos. Hacia el andaluz, por su parte, manifiestan también actitudes positivas, pero lo hacen en menor proporción que hacia el castellano y, normalmente, en otras cualidades que podrían verse más cercanas a la solidaridad: familiar, cercana, divertida y bonita. Como se ha visto a lo largo del trabajo, muchos de los datos expuestos presentan tendencias muy similares en otros estudios de actitudes. Por ejemplo, parece existir una generalidad por parte de las mujeres a mostrar una mejor valoración de la pauta de pronunciación del castellano, variedad que consideran modelo idiomático normativo. Asimismo, también se aprecia una mejor evaluación del discurso oral en la variedad propia (no siendo así en la variedad ajena) y una asignación preferente de ciertas cualidades al andaluz (divertida, cercana, familiar o bonita) y de otras al castellano (avanzada, rica, interesante o innovadora). Será interesante comprobar en el futuro si este tipo de actitudes son exclusivas del perfil tan específico que se ha analizado aquí (jóvenes mallorquines estudiantes de filología) o si estas evaluaciones pueden extrapolarse a otros sectores de población de la isla. 


\section{BIBLIOGRAFÍA}

BAKER, Colin (1992): Attitudes and Language, Clevedon: Multilingual Matters.

Buzón García, José María, María Begoña Gómez Devís y José Ramón Gómez Molina (2017): Actitudes lingüisticas en Valencia y su área metropolitana. Estudio longitudinal y análisis de tendencias, Valencia: Tirant Humanidades.

Casesnoves Ferrer, Raquel y Josep Ángel Más Castells (2017): «Ideology and Language Choice: Catalan-speaking University Students», Sociolinguistic Studies $11 / 1,107-129$.

Cestero Mancera, Ana María y Florentino Paredes García (2018a): «Creencias y actitudes hacia las variedades cultas del español actual: el proyecto PRECAVES XXI», Boletín de Filología 53/2, 11-43.

— y - (2018b): «Creencias y actitudes de los jóvenes universitarios del centronorte de España hacia las variedades cultas del español», Boletín de Filología 53/2, 45-86.

Crano, William D. y Radmila Prislin (2006): «Attitudes and Persuasion», Annual Review of Psychology 57, 345-374.

Crespo Cano, Virgilio y Antonio Manjón Cabeza Cruz (1996): «Aproximación a las actitudes y creencias lingüísticas de futuros maestros», Docencia e Investigación 21, 41-76.

Gallego, Juan Carlos y Anthony Rodríguez (2012): «Castilian Speakers' Attitudes towards Accents and Regional Stereotypes in Spain», Sociolinguistic studies 6/3, 543-569.

Henerson, Marlene E., Lynn Lyons Morris y Carol Taylor Fitz-Gibbon (1987): How to Measure Attitudes, London: SAGE Publications.

Hernández Cabrera, Clara E. y Marta Samper Hernández (2018): «Creencias y actitudes de los jóvenes universitarios canarios hacia las variedades cultas del español», Boletín de Filología 53/2, 179-208.

Hernández CAMPOY, Juan Manuel (2004): «El fenómeno de las actitudes y su medición en sociolingüística», Tonos digital 8, 29-56.

López Morales, Humberto (2004): Sociolingüistica, Madrid: Gredos.

Manjón Cabeza Cruz, Antonio (2000): «Actitudes de los transmisores del prestigio lingüístico en Toledo: primeros datos», Docencia e Investigación 25, 89-123.

- (2018): «Creencias y actitudes de los jóvenes universitarios granadinos hacia las variedades cultas del español», Boletín de Filología 53/2, 145-177.

MÉNDEZ Guerrero, Beatriz (2018): «Creencias y actitudes de los jóvenes universitarios mallorquines hacia las variedades cultas del español», Boletín de Filología $53 / 2,87-114$.

- (en prensa a): «Actitudes de los mallorquines hacia el castellano y el andaluz. Datos del proyecto PRECAVES XXI», Revista española de lingüistica aplicada (RESLA).

- (en prensa $b)$ : «Percepciones lingüísticas de los jóvenes universitarios mallorquines hacia el andaluz», Philologia Hispalensis. 
Moreno Fernández, Francisco (2009): La lengua española en su geografía, Madrid: Arco/Libros.

- (2012): «Percepciones de la lengua española», Boletín de la Academia Cubana de la Lengua 17, 5-20.

- y Jaime Otero Roth (2007): Atlas de la lengua española en el mundo, Barcelona: Ariel/Fundación Telefónica/Instituto Cervantes.

Paredes García, Florentino y Ana María Cestero Mancera (2018): «Percepción de las variedades cultas del español por hablantes del centro-norte de España según los datos del proyecto PRECAVES XXI: el español ejemplar y la variedad propia», Oralia 21, 87-112.

Pieras-GuasP, Felipe (2002): «Direct vs. Indirect Attitude Measurement and the Planning of Catalan in Mallorca», Language Problems and Language Planning 26/1, 51-68.

Preston, Denis R. (1999): Manual de Dialectología Perceptual, vol. 1, Ámsterdam: John Benjamins.

SANTANA MARRERo, Juana (2018a): «Creencias y actitudes de los jóvenes universitarios sevillanos hacia las variedades cultas del español», Boletín de Filología $53 / 2,115-144$.

- (2018b): «Creencias y actitudes de jóvenes universitarios sevillanos hacia las variedades normativas del español de España: andaluza, canaria y castellana», Pragmática Sociocultural (Soprag) 6/1, 71-97.

SAVILle-Troike, Muriel (2003): The Ethnography of Communication: An Introduction, Malden, MA: Blackwell Publishers Ltd.

YraOla, Aitor (2014): «Actitudes lingüísticas en España». En Ana Beatriz Chiquito y Miguel Ángel Quesada Pacheco (eds.), Actitudes lingüisticas de los hispanohablantes hacia el idioma español y sus variantes, Bergen Language and Linguistic Studies (BeLLS), 5, 551-636. 